\title{
A phase II dose-response study of hemoglobin raffimer (Hemolink) in elective coronary artery bypass surgery
}

\author{
D. C. H. Cheng, MD, MSc, FRCPC ${ }^{a}$ \\ C. D. Mazer, MD, FRCPC ${ }^{b}$ \\ R. Martineau, MD ${ }^{\mathrm{C}}$ \\ A. Ralph-Edwards, BSc, MD, FRCSC, FACS ${ }^{d}$ \\ J. Karski, MD ${ }^{\mathrm{d}}$ \\ J. Robblee, BSc, MBA, MD, FRCPC \\ B. Finegan, MB, FFARCS(I), FRCPC ${ }^{f}$ \\ R. I. Hall, BScPharm, MD, FRCPC, FCCPg \\ R. Latimer, MA, MBBS, LRCP, MRCS, FRCA ${ }^{\text {h }}$ \\ A. Vuylsteke, $M D^{\mathrm{h}}$
}

\begin{abstract}
From London Health Sciences Center, University of Western Ontario, London, On-

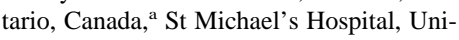
versity of Toronto, Toronto, Ontario, Canada, ${ }^{\mathrm{b}}$ Montreal Heart Institute, Montreal, Quebec, Canada, ${ }^{\mathrm{c}}$ Toronto General Hospital, University of Toronto, Toronto, Ontario, Canada, ${ }^{\mathrm{d}}$ University of Ottawa Heart Institute, Ottawa, Ontario, Canada, ${ }^{e}$ University of Alberta Hospitals, Edmonton, Alberta, Canada, ${ }^{f}$ Queen Elizabeth II Health Sciences Centre, Halifax, Nova Scotia, Canada, ${ }^{\mathrm{g}}$ and Papworth Hospital, Papworth, Cambridge, United Kingdom. ${ }^{\mathrm{h}}$
\end{abstract}

This study was supported by a research grant from Hemosol Inc.

Received for publication Dec 10, 2002; revisions requested Aug 21, 2003; revisions received Aug 25, 2003; accepted for publication Aug 25, 2003.

Address for reprints: Davy Cheng, MD MSc, FRCPC, Department of Anesthesia \& Perioperative Medicine, University of Western Ontario, London Health Sciences Center, 339 Windermere Rd, 3-CA 19, London, Ontario, Canada N6A 5A5 (Email: davy.cheng@uwo.ca).

J Thorac Cardiovasc Surg 2004;127:79-86 $0022-5223 / \$ 30.00$

Copyright ( $\odot 2004$ by The American Association for Thoracic Surgery

doi:10.1016/j.jtcvs.2003.08.024
Background: We performed this study to determine the dose-response of hemoglobin raffimer administered in conjunction with intraoperative autologous donation in patients undergoing coronary artery bypass grafting surgery. A secondary objective was to evaluate hemoglobin raffimer for reducing the incidence of allogeneic red blood cell transfusions.

Methods: This was a phase II, single-blind, multicenter, placebo-controlled, openlabel study. Patients undergoing coronary artery bypass grafting with cardiopulmonary bypass and intraoperative autologous donation were randomized to receive a single dose of hemoglobin raffimer or control (10\% pentastarch). Patients were sequentially enrolled in a dose block of $250,500,750$, and $1000 \mathrm{~mL}$.

Results: Sixty patients received hemoglobin raffimer $(\mathrm{n}=30)$ or control $(\mathrm{n}=30)$. Hemoglobin raffimer was well tolerated. Most (98\%) adverse events were mild or moderate in severity. There was an expected dose-dependent increase in the incidence of blood pressure increases and jaundice in hemoglobin raffimer-treated patients. In a dose-pooled analysis of hemoglobin raffimer versus control, increased blood pressure ( $43 \%$ vs $17 \%)$, nausea ( $37 \%$ vs $33 \%)$, and atrial fibrillation ( $37 \%$ vs $17 \%$ ) were the most frequently reported adverse events. All serious adverse events were considered unrelated or unlikely to be related to study drug. No hemoglobin raffimer-treated patient required an intraoperative allogeneic red blood cell transfusion, compared with $5(17 \%)$ pentastarch-treated patients $(P=.052)$. This advantage of hemoglobin raffimer was maintained at 24 hours after surgery (7\% vs $37 \% ; P=.010)$ and up to 5 days after surgery $(10 \%$ vs $47 \% ; P=.0034)$.

Conclusions: Hemoglobin raffimer was not associated with any serious adverse events in patients undergoing primary coronary artery bypass grafting with cardiopulmonary bypass and intraoperative autologous donation in a dose-response study up to $1000 \mathrm{~mL}$. Hemoglobin raffimer was effective in facilitating decreased exposure or avoidance of allogeneic red blood cell transfusions when used in conjunction with intraoperative autologous donation.

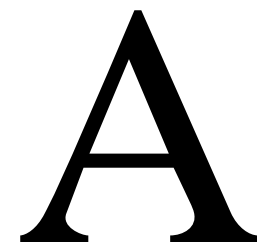

lthough blood transfusion is now a generally safe procedure, cases of ABO incompatibility, bacterial contamination, and viral contamination are still reported and can be life threatening. ${ }^{1,2}$ Bleeding after coronary artery bypass grafting $(\mathrm{CABG})$ can be a major surgical complication, and excessive bleeding contributes to postoperative morbidity and mortality and the need for transfusion. ${ }^{3,4}$ In the United States, an estimated $20 \%$ of allogeneic blood transfusions occur in 
cardiac surgical patients. ${ }^{5}$ Continued concern over the safety of red blood cell (RBC) transfusions has fostered alternative strategies for treating bleeding in patients having CABG surgery, ${ }^{6}$ such as blood conservation by intraoperative autologous donation (IAD) to reduce patient need for banked blood. This technique involves the removal of several units of a patient's blood immediately before operation. This collected blood is held on reserve in the operating room for retransfusion when the patient reaches a specified transfusion trigger. In the IAD procedure, the harvested blood volume is replaced with a plasma expander or an oxygen carrier. Several oxygen carriers, members of a new pharmacologic class called hemoglobin-based oxygen carriers, are in clinical development.

Hemoglobin raffimer, an oxidized raffinose cross-linked human hemoglobin (Hemolink; Hemosol Inc, Toronto, Ontario, Canada), is a highly purified hemoglobin-based oxygen carrier prepared from human RBCs. The manufacturing process and product specifications for hemoglobin raffimer have previously been described. ${ }^{7}$ The cross-linking of the hemoglobin moiety results in a stabilized hemoglobin molecule with an increased plasma half-life and improves oxygen offloading by decreasing the hemoglobin component's affinity for oxygen. ${ }^{8}$ Hemoglobin raffimer has been evaluated in healthy volunteers to determine the tolerability, pharmacokinetics, and pharmacodynamics of increasing doses. ${ }^{9}$ Hemoglobin raffimer is distributed mainly in the plasma, with peak concentrations consistent with a volume of distribution equal to the plasma volume. Similar to endogenous hemoglobin, hemoglobin raffimer seems to be catabolized via the heme oxygenase pathway, resulting in transient increases in serum bilirubin levels that are proportional to the hemoglobin raffimer dose. ${ }^{9}$ As a result of the acceptable tolerance and pharmacokinetic profile in healthy volunteers, hemoglobin raffimer was further assessed in a phase II study.

The objective of this phase II trial was to evaluate the effects and efficacy of escalating doses of hemoglobin raffimer administered in conjunction with IAD on tissue oxygenation and on reducing the incidence and volume of allogeneic RBC transfusions in patients undergoing $\mathrm{CABG}$ surgery.

\section{Methods}

\section{Patient Eligibility}

Men and women from 18 to 80 years of age who were scheduled for primary elective CABG surgery with cardiopulmonary bypass (CPB) were eligible for inclusion in the study. Eligible patients had a hematocrit level that would allow harvesting of 500 to $1500 \mathrm{~mL}$ of intraoperative autologous blood to reach an on-CPB target hematocrit level of 0.20 to 0.24 . Exclusion criteria included a history of cardiac surgery, myocardial infarction (MI) within 4 weeks before the scheduled operation, congestive heart failure, left ventricular ejection fraction of less than $30 \%$, and clinically sig- nificant renal, liver, or pancreatic disease. The study was conducted in accordance with the Declaration of Helsinki (Republic of South Africa, Oct 1996) and was approved by the institutional review boards of the participating study centers. All patients provided written, informed consent.

\section{Study Design and Treatment}

This randomized, single-blind, controlled, open-label study was conducted at multiple sites in Canada (6 sites) and in the United Kingdom (1 site). All patients underwent operation via a median sternotomy with saphenous veins, internal thoracic arteries, or both, as conduits according to each institution's standard procedure. Patients were screened before operation and were randomized in a 1:1 ratio to receive hemoglobin raffimer or $10 \%$ pentastarch (Pentaspan), which served as the control. Four dose blocks were established that consisted of escalating volumes $(250,500$, 750 , and $1000 \mathrm{~mL}$ ) of hemoglobin raffimer and pentastarch. The doses were chosen on the basis of the volumes estimated to be used clinically. Patients were sequentially enrolled starting with the lowest-volume dose block, and dose block enrollment was completed in respective order. Autologous blood was harvested after heparinization and immediately before initiation of CPB. A single dose of hemoglobin raffimer or pentastarch was administered as a $1: 1$ volume replacement by addition into the bypass pump reservoir at initiation of CPB. The volume of autologous blood to be collected was calculated by using the formula

Volume $=[(70 \mathrm{~mL} / \mathrm{kg})($ weight $)(\mathrm{Hb}-7 \mathrm{~g} / \mathrm{dL})]$

$$
-[(7 \mathrm{~g} / \mathrm{dL})(\text { prime }+750 \mathrm{~mL})] \times \mathrm{Hb},
$$

where volume is the volume in milliliters of autologous blood to be collected, weight is the patient's body weight in kilograms, hemoglobin is measured hemoglobin in grams per deciliter, and prime is the estimated pump prime volume in milliliters.

All autologous blood donated at the beginning of the bypass procedure was returned to the patient either when a protocoldefined transfusion trigger was reached during the operation or at the completion of the surgical procedure, regardless of the hemoglobin level.

Crystalloid solution was infused as required for additional volume management. Transfusions were administered on the basis of specific transfusion triggers, as defined by the consensus of a core group of investigators, and represent their standards of clinical practice. A transfusion trigger was defined as hemoglobin less than $6.0 \mathrm{~g} / \mathrm{dL}$ or less than $65 \%$ oxygen saturation of mixed venous blood during CPB and as hemoglobin less than $7.0 \mathrm{~g} / \mathrm{dL}$ or less than $65 \%$ oxygen saturation of mixed venous blood after CPB. In the intensive care unit (ICU), after the removal of the pulmonary artery catheter, the transfusion trigger was hemoglobin less than $7.5 \mathrm{~g} / \mathrm{dL}$ or hematocrit less than 0.24 ; on the ward, it was hemoglobin less than $8.0 \mathrm{~g} / \mathrm{dL}$ or hematocrit less than 0.27 .

\section{Adverse Events and Efficacy Measurements}

Patients were monitored in the hospital (typically 4 to 7 days) and assessed at a follow-up visit 5 to 8 weeks after discharge. Assessments were performed during the patient's hospital stay and at the follow-up visit and included adverse events, laboratory measurements (including clinical chemistry, cardiac enzymes, hematology, 
TABLE 1. Patient demographics

\begin{tabular}{|c|c|c|c|c|c|c|c|c|}
\hline \multirow[b]{2}{*}{ Characteristic } & \multicolumn{4}{|c|}{ Hb raffimer $(\mathrm{mL})(\mathrm{n}=30)$} & \multicolumn{4}{|c|}{ Pentastarch $(\mathrm{mL})(\mathrm{n}=30)$} \\
\hline & 250 & 500 & 750 & 1000 & 250 & 500 & 750 & 1000 \\
\hline \multicolumn{9}{|l|}{$\operatorname{Sex}(n)$} \\
\hline Male & 4 & 5 & 8 & 9 & 4 & 3 & 8 & 7 \\
\hline Female & 1 & 0 & 2 & 1 & 1 & 2 & 2 & 3 \\
\hline \multicolumn{9}{|l|}{ Age (y) } \\
\hline Mean & 68 & 57 & 60 & 58 & 58 & 66 & 61 & 64 \\
\hline Range & $63-73$ & $47-69$ & $42-71$ & $47-74$ & $43-68$ & $61-70$ & $38-75$ & $48-74$ \\
\hline \multicolumn{9}{|l|}{ Weight (kg) } \\
\hline Mean & 84 & 77 & 83 & 84 & 78 & 79 & 79 & 81 \\
\hline Range & $76-89$ & $65-85$ & $68-93$ & $66-117$ & $68-89$ & $72-88$ & $64-100$ & $54-99$ \\
\hline \multicolumn{9}{|l|}{ Race } \\
\hline Caucasian & 5 & 4 & 9 & 10 & 3 & 5 & 9 & 8 \\
\hline Other & 0 & 1 & 1 & 0 & 2 & 0 & 1 & 2 \\
\hline
\end{tabular}

$H b$, Hemoglobin.

urinalysis, and anti-hemoblobin raffimer antibody), blood gases, fluid input and output, mediastinal chest-drain volumes, electrocardiograms (ECGs), vital signs, and physical examinations. The presence of hemoglobin raffimer may interfere with some clinical laboratory tests because of the characteristic absorption pattern of hemoglobin. Interference testing was performed at the central laboratory and at all local laboratories that analyzed patient samples from this study. Correction factors were applied at each laboratory and for each analyte as appropriate. A blinded, independent cardiologist and the Safety Monitoring Committee (blinded) assessed the ECG and myocardial muscle creatine kinase isoenzyme (CK-MB) data for all patients after each dose block. The diagnosis of MI was based on a combination of ECG changes and myocardial enzyme increases. A definitive MI was defined as a new $\mathrm{Q}$ wave, new left bundle branch block, or new pathologic $\mathrm{R}$ waves in combination with a CK-MB greater than $40 \mathrm{ng} / \mathrm{mL}$ at 12 hours after crossclamp removal. A probable MI was defined as a new ischemic ECG abnormality or loss of $\mathrm{R}$ wave in combination with a CK-MB clamp $40 \mathrm{ng} / \mathrm{mL}$ at 12 hours after crossclamp removal. Enzyme increases alone were not considered diagnostic of an MI.

Serum samples were screened for antibodies by using a solidphase, enzyme-linked immunosorbent assay to measure the presence of anti-hemoglobin raffimer immunoglobulin $\mathrm{G}$ and immunoglobulin $\mathrm{M}$ reactivity before and after infusion of hemoglobin raffimer or pentastarch. Results were determined to be negative if they were less than the mean plus $3 \mathrm{SD}$ of the results from an untreated population (data not shown). Positive screening results were confirmed by adsorption on hemoglobin raffimer-coated Sepharose $4 \mathrm{~B}$ and retesting by the enzyme-linked immunosorbent assay method.

Efficacy assessments included systemic oxygenation measurements (oxygen saturation in arterial and venous blood, lactate, base excess, oxygen delivery and consumption, and oxygen extraction coefficient or ratio). Arterial and mixed venous blood gas measurements were performed at 15-minute intervals during operation and then at 1,6 , and 24 hours after surgery as long as pulmonary artery and radial arterial catheters were in place. The incidence of intraoperative autologous transfusions and the incidence and vol- ume of perioperative allogeneic blood transfusions were also determined.

\section{Statistical Methods}

Data were converted to SAS (SAS Institute, Cary, NC) data sets by using SAS System, release 6.12. The frequencies of treatmentemergent adverse events were coded with the COSTART system (Coding Symbols for a Thesaurus of Adverse Reaction Terms; US Food and Drug Administration, 1993). Summary statistics were calculated for demographic and laboratory values. All treated patients were included in the primary and secondary outcome analyses. Descriptive statistics, including mean, n, SD, and SEM, were calculated for all numeric efficacy variables. Data on systemic oxygenation parameters were analyzed with the repeated-measures analysis of variance method. A $\chi^{2}$ test was used to detect the difference in frequency distribution of allogeneic transfusions.

\section{Results \\ Patient Demographics}

A total of 79 patients were enrolled in the study. Of these patients, 13 were eliminated by the screening process, and 6 were randomization failures (patients who passed the initial screening process and were randomized to a treatment group but were discontinued from the study before receiving study medication). Sixty patients received study treatment (hemoglobin raffimer or pentastarch), and 53 patients completed the study. Seven patients did not complete the study -3 voluntarily withdrew from the study, and 4 did not attend the follow-up visit. Five of the 7 patients who discontinued were in the hemoglobin raffimer groups (1 each from the 250-, 500-, and 1000-mL dose blocks and 2 from the 750-mL dose block). Patient demographics are summarized in Table 1. No significant differences were observed among the treatment groups for any demographic parameter. IAD harvest volume (mean $\pm \mathrm{SD}$ ) was comparable in 


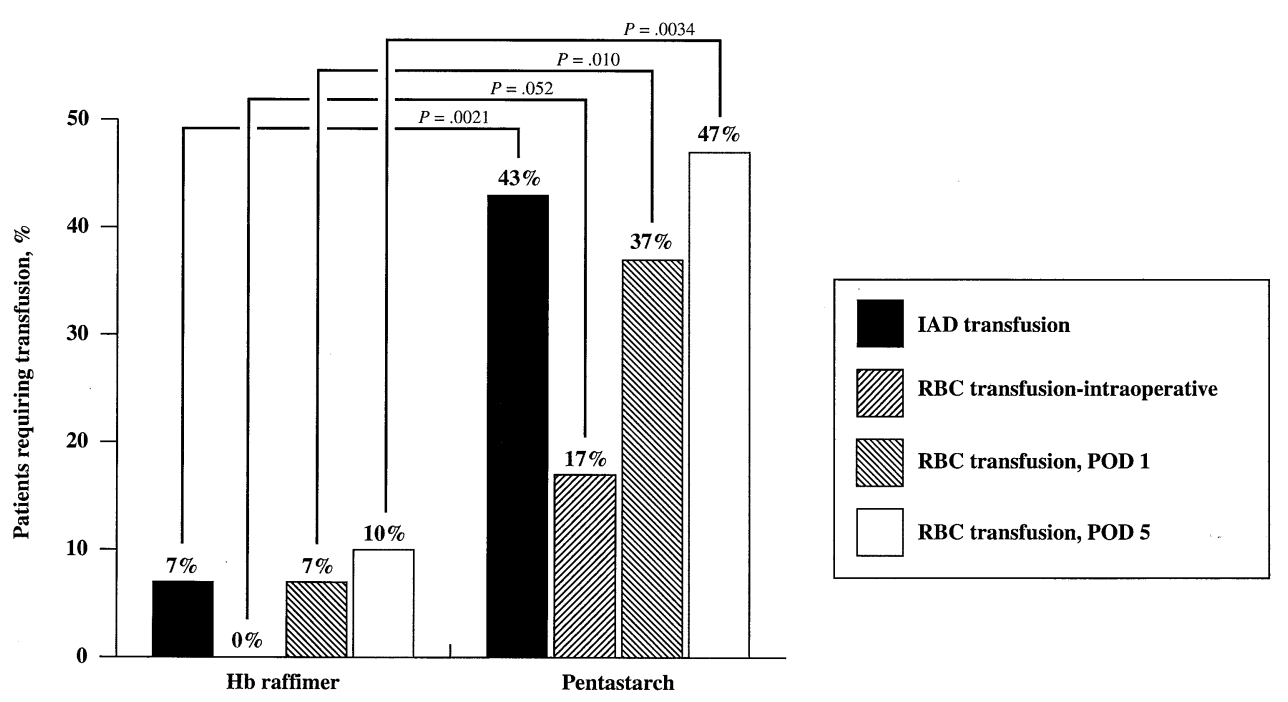

Figure 1. Percentage of patients undergoing coronary artery bypass grafting with cardiopulmonary bypass who required a transfusion. $H b$, Hemoglobin; $I A D$, intraoperative autologous donation; $R B C$, red blood cell; $P O D$, postoperative day.

both study groups, with $1100 \pm 345 \mathrm{~mL}$ collected in the hemoglobin raffimer patients and $952 \pm 269 \mathrm{~mL}$ in the control patients.

\section{Efficacy Outcomes}

All randomized patients who received study treatment were included in the efficacy analysis. The incidence of IAD transfusions (Figure 1 and Table 2$)$ was significantly $(P=$ .0021) lower in hemoglobin raffimer-treated patients compared with pentastarch-treated patients (7\% vs $43 \%$ ). Furthermore, no patient treated with hemoglobin raffimer required an intraoperative transfusion of allogeneic RBCs, whereas $5(17 \%)$ pentastarch-treated patients required a transfusion $(P=.052)$. Significantly fewer hemoglobin raffimer-treated patients required an RBC transfusion compared with pentastarch-treated patients up to 24 hours after surgery (7\% vs $37 \% ; P=.010)$ and up to 5 days after surgery ( $10 \%$ vs $47 \% ; P=.0034)$. The overall mean time to the first transfusion trigger was longer in the hemoglobin raffimer group compared with the pentastarch group by approximately 5 hours.

Among patients who received RBC transfusions over the study duration, the 3 hemoglobin raffimer-treated patients received a smaller average volume (ie, fewer units) than the 14 pentastarch-treated patients $(367 \pm 29 \mathrm{~mL}$ vs $890 \pm 818$ $\mathrm{mL}$ ). However, this difference was not statistically significant.

There was also an expected increase in whole blood total hemoglobin in hemoglobin raffimer-treated patients compared with pentastarch-treated patients. In addition, serum hemoglobin levels increased rapidly after hemoglobin raf- fimer infusion and were dose dependent. Mean peak serum hemoglobin levels $(5.8,9.8,15.5$, and $17.8 \mathrm{~g} / \mathrm{dL}$ for the 250-, 500-, 750-, and 1000-mL dose blocks, respectively) were observed in serum samples analyzed within 1 hour after operation. Mean serum hemoglobin levels returned to predose levels by 24 hours in the $250-\mathrm{mL}$ dose block and by 48 hours in the 500- and 750-mL dose blocks, respectively. The mean serum hemoglobin level remained slightly increased in the 1000-mL hemoglobin raffimer group at 48 hours after surgery but returned to baseline by postoperative day 5 . The mean hematocrit values at postoperative day 5 (or discharge) were $0.29 \pm 0.03$ for patients treated with hemoglobin raffimer and $0.30 \pm 0.04$ for patients treated with pentastarch.

\section{Adverse Events}

Hemoglobin raffimer was not associated with any serious adverse events in an escalating dose up to $1000 \mathrm{~mL}$. Blood gas measurements were stable and comparable across all treatment groups, as were fluid input and output measures and mediastinal chest-drain volumes. Adverse events reported by treatment group in each dose block are shown in Table 3. Most (98\%) adverse events were mild or moderate in severity and were transient. There were expected dosedependent increases in the incidence of transient increases in blood pressure and jaundice in hemoglobin raffimertreated patients. After adverse events were analyzed by study drug dose, the data were pooled for the 4 dose blocks of hemoglobin raffimer and pentastarch. The most frequently reported adverse events reported in this pooled analysis are summarized in Table 4 . Blood pressure in- 
TABLE 2. Incidence of transfusions by treatment dose

\begin{tabular}{|c|c|c|c|c|c|c|c|c|}
\hline \multirow[b]{2}{*}{ Variable } & \multicolumn{4}{|c|}{ Hb raffimer $(\mathrm{mL})$} & \multicolumn{4}{|c|}{ Pentastarch (mL) } \\
\hline & $\begin{array}{c}250 \\
(n=5)\end{array}$ & $\begin{array}{c}500 \\
(n=5)\end{array}$ & $\begin{array}{c}750 \\
(n=10)\end{array}$ & $\begin{array}{c}1000 \\
(n=10)\end{array}$ & $\begin{array}{c}250 \\
(n=5)\end{array}$ & $\begin{array}{c}500 \\
(n=5)\end{array}$ & $\begin{array}{c}750 \\
(n=10)\end{array}$ & $\begin{array}{c}1000 \\
(n=10)\end{array}$ \\
\hline IAD transfusion & 1 & 0 & 1 & 0 & 2 & 1 & 5 & 5 \\
\hline \multicolumn{9}{|l|}{ Allogeneic RBC transfusion } \\
\hline Intraoperative & 0 & 0 & 0 & 0 & 1 & 1 & 2 & 1 \\
\hline POD 1 & 0 & 1 & 0 & 1 & 1 & 2 & 3 & 5 \\
\hline POD 5 & 0 & 1 & 1 & 1 & 2 & 3 & 4 & 5 \\
\hline
\end{tabular}

$H b$, Hemoglobin; $I A D$, intraoperative autologous donation; $R B C$, red blood cell; $P O D$, postoperative day.

Data are number of patients.

TABLE 3. Adverse events reported by treatment group

\begin{tabular}{|c|c|c|c|c|c|c|c|c|}
\hline \multirow[b]{2}{*}{ Adverse event } & \multicolumn{4}{|c|}{$\mathrm{Hb}$ raffimer $(\mathrm{mL})$} & \multicolumn{4}{|c|}{ Pentastarch (mL) } \\
\hline & $\begin{array}{c}250 \\
(n=5)\end{array}$ & $\begin{array}{c}500 \\
(n=5)\end{array}$ & $\begin{array}{c}750 \\
(n=10)\end{array}$ & $\begin{array}{c}1000 \\
(n=10)\end{array}$ & $\begin{array}{c}250 \\
(n=5)\end{array}$ & $\begin{array}{c}500 \\
(n=5)\end{array}$ & $\begin{array}{c}750 \\
(n=10)\end{array}$ & $\begin{array}{c}1000 \\
(n=10)\end{array}$ \\
\hline Hypertension & 0 & $2(40)$ & $6(60)$ & $5(50)$ & 0 & $2(40)$ & $3(30)$ & 0 \\
\hline Nausea & 0 & $2(40)$ & $6(60)$ & $3(30)$ & $1(20)$ & $1(20)$ & $3(30)$ & $6(60)$ \\
\hline Atrial fibrillation & $2(40)$ & $2(40)$ & $2(20)$ & $5(50)$ & $1(20)$ & $2(40)$ & 0 & $2(20)$ \\
\hline Jaundice & 0 & $1(20)$ & $4(40)$ & $8(80)$ & 0 & 0 & 0 & 0 \\
\hline Myocardial infarction & $2(40)$ & $1(20)$ & 0 & $3(30)$ & $4(80)$ & $1(20)$ & $1(10)$ & $2(20)$ \\
\hline Fever & $1(20)$ & $1(20)$ & $2(20)$ & $2(20)$ & 0 & $1(20)$ & $3(30)$ & $3(30)$ \\
\hline Increased amylase & 0 & $1(20)$ & $3(30)$ & $2(20)$ & $2(40)$ & 0 & 0 & $3(30)$ \\
\hline Hypotension & 0 & $1(20)$ & $2(20)$ & $3(30)$ & 0 & 0 & $2(20)$ & $2(20)$ \\
\hline Pain & 0 & $2(40)$ & $3(30)$ & $1(10)$ & 0 & 0 & $1(10)$ & $1(10)$ \\
\hline Dizziness & $1(20)$ & $1(20)$ & $3(30)$ & 0 & 0 & 0 & $1(10)$ & $1(10)$ \\
\hline Abnormal liver function tests & 0 & $1(20)$ & $1(10)$ & $4(40)$ & 0 & $1(20)$ & 0 & $1(10)$ \\
\hline Infection & 0 & 0 & 0 & 0 & $1(20)$ & 0 & $3(30)$ & 0 \\
\hline Diarrhea & 0 & $2(40)$ & 0 & 0 & $1(20)$ & 0 & $1(10)$ & 0 \\
\hline Impaired urination & 0 & 0 & 0 & 0 & $2(40)$ & 0 & 0 & 0 \\
\hline
\end{tabular}

$\mathrm{Hb}$, Hemoglobin.

Data are number of patients $(\%)$.

creases, nausea, atrial fibrillation, and jaundice were among the events reported more frequently with hemoglobin raffimer treatment than with pentastarch treatment.

There were 4 reports of severe adverse events in the hemoglobin raffimer-treated group and 3 in the pentastarchtreated group. One severe adverse event (arterial hypertension) was reported in the 500-mL hemoglobin raffimer group. Congestive heart failure/malaise, increased amylase, and supraventricular tachycardia were reported in the 1000-mL hemoglobin raffimer group. A sternal wound infection and stroke were reported as severe adverse events in the $250-\mathrm{mL}$ pentastarch group, and ventricular fibrillation was reported in the 750-mL pentastarch group. In addition, 6 hemoglobin raffimer-treated and 9 pentastarch-treated patients experienced a total of 17 serious adverse events, which required longer hospitalization. All 17 of these serious events were considered by the investigator to be unrelated or unlikely to be related to the study drug. No deaths occurred during the study.
Increased blood pressure occurred more often in hemoglobin raffimer-treated patients (13 of 30;43\%) than in pentastarch-treated patients ( 5 of $30 ; 17 \%$ ). Most blood pressure increases in hemoglobin raffimer-treated patients occurred in the ICU, returned to baseline levels within 24 hours, and were mild to moderate in magnitude, ranging from $1 \%$ to $4 \%$ in the $750-\mathrm{mL}$ dose blocks and $14 \%$ to $25 \%$ in the $500-\mathrm{mL}$ dose blocks. Only 4 hemoglobin raffimertreated patients and 1 pentastarch-treated patient experienced a $25 \%$ or more increase in mean arterial pressure. According to the investigators' assessment, 6 patients in the hemoglobin raffimer group and 8 patients in the pentastarch group had MIs reported as adverse events.

\section{Biochemical Outcomes}

There were no unexpected differences in clinical laboratory measurements in the hemoglobin raffimer and control groups, with the exception of serum lipase, which was increased in 7 (23\%) hemoglobin raffimer-treated patients. 
TABLE 4. Pooled adverse events reported by treatment group

\begin{tabular}{lccc}
\hline Adverse event & $\begin{array}{c}\text { Hb raffimer } \\
(\mathbf{n}=\mathbf{3 0})\end{array}$ & $\begin{array}{c}\text { Pentastarch } \\
(\mathbf{n}=\mathbf{3 0})\end{array}$ & $\begin{array}{c}\boldsymbol{P} \\
\text { value* }\end{array}$ \\
\hline Hypertension & $13(43)$ & $5(17)$ & .047 \\
Nausea & $11(37)$ & $10(33)$ & .79 \\
Atrial fibrillation & $11(37)$ & $5(17)$ & .14 \\
Jaundice & $11(37)$ & 0 & .0008 \\
Myocardial infarction & $6(20)$ & $8(27)$ & .76 \\
Fever & $6(20)$ & $7(23)$ & .75 \\
Increased amylase & $6(20)$ & $5(17)$ & .74 \\
Hypotension & $6(20)$ & $4(13)$ & .73 \\
Pain & $6(20)$ & $2(7)$ & .25 \\
Dizziness & $5(17)$ & $2(7)$ & .42 \\
Vomiting & $5(17)$ & $2(7)$ & .42 \\
Abnormal liver function tests & $5(17)$ & $2(7)$ & .42 \\
Hemorrhage & $4(13)$ & $3(10)$ & .69 \\
Dyspnea & $1(3)$ & $4(13)$ & .35 \\
Rash & $4(13)$ & 0 & .12 \\
Infection & 0 & $4(13)$ & .12 \\
Increased cough & $3(10)$ & 0 & .24 \\
Myocardial ischemia & $3(10)$ & 0 & .24 \\
\hline
\end{tabular}

$H b$, Hemoglobin.

Data are number of patients $(\%)$.

*Two-tailed Fisher exact test.

The mean lipase level for hemoglobin raffimer-treated patients was $403 \mathrm{U} / \mathrm{L}$ (upper limit of normal, $190 \mathrm{U} / \mathrm{L}$ ), with a peak at 24 hours after surgery, and it returned to normal levels by 48 to 72 hours. The mean lipase level for pentastarch-treated patients did not exceed the reference range. In addition, there was an increase in mean amylase levels in $20(67 \%)$ hemoglobin raffimer-treated patients, with a peak mean amylase level of $293 \pm 196 \mathrm{U} / \mathrm{L}$ at 24 hours, whereas $26(86 \%)$ controls had increased amylase levels, with a peak mean of $304 \pm 149 \mathrm{U} / \mathrm{L}$ at 24 hours. Amylase levels returned to the reference range (upper limit of normal, 220 U/L) by 48 to 72 hours after surgery. None of the observed increases in serum amylase or lipase levels were accompanied by clinical signs or symptoms of pancreatitis.

After infusion of hemoglobin raffimer, total bilirubin levels demonstrated an expected dose-related increase within 24 hours after surgery. Bilirubin levels began to decline by 48 hours and returned to baseline by 72 hours after surgery. Mean total bilirubin values at 24 hours ranged from $21.1 \mu \mathrm{mol} / \mathrm{L}$ in the $250-\mathrm{mL}$ hemoglobin raffimer group to $46.7 \mu \mathrm{mol} / \mathrm{L}$ in the $1000-\mathrm{mL}$ hemoglobin raffimer group. Liver enzymes (alkaline phosphatase, alanine aminotransferase, aspartate aminotransferase, and $\gamma$-glutamyltransferase) were similar across all dose groups and both treatment groups. Systemic oxygenation was assessed in both arterial and mixed venous blood. Oxygenation parameters for combined dose blocks at the 45-minute time point during $\mathrm{CPB}$ and in the ICU are shown in Table 5. Oxygen delivery rates and measurements of oxygenation variables in mixed venous blood were consistently higher in hemoglobin raffimer-treated patients than in pentastarch-treated patients during CPB but were not statistically different. Oxygenation parameters in arterial blood demonstrated no statistically significant difference between treatment groups. After CPB, these variables were similar in both treatment groups. Oxygen consumption rates and oxygen extraction rates were similar in hemoglobin raffimer-treated and pentastarch-treated patients, both during CPB and in the ICU.

Patients were also tested for immunoreactivity to hemoglobin raffimer. Pretreatment samples were obtained for 27 pentastarch-treated and 29 hemoglobin raffimer-treated patients. Posttreatment samples were collected at the follow-up 4- to 6-week postsurgery visit for 22 pentastarchtreated and 23 hemoglobin raffimer-treated patients. In these subsets, no patient exhibited immunoreactivity toward hemoglobin raffimer before study treatment, and $4(17 \%)$ hemoglobin raffimer-treated patients $(3$ receiving $500 \mathrm{~mL}$ and 1 receiving $1000 \mathrm{~mL}$ of hemoglobin raffimer) showed immunoreactivity after study treatment. Skin rash $(n=4)$ and pruritus $(\mathrm{n}=1)$ were reported in hemoglobin raffimertreated patients during the study. However, only 1 episode of rash, which occurred in a patient who received $500 \mathrm{~mL}$ of hemoglobin raffimer and who tested positive for anti-hemoglobin raffimer antibody, was considered possibly related to study medication.

\section{Discussion}

Because of the risks associated with allogeneic blood transfusion, there has been increasing interest in the clinical development of oxygen delivery systems to facilitate blood conservation. This study examined the efficacy, adverse events, and biochemical profile of escalating doses (250 to $1000 \mathrm{~mL}$ ) of hemoglobin raffimer in patients undergoing CABG. In this study, increased blood pressure, atrial fibrillation, and jaundice were the most frequently reported adverse events in hemoglobin raffimer-treated patients.

In general, the adverse events reported in this study were similar to events commonly reported in the literature for CABG patients. ${ }^{10,11}$ The most frequently reported cardiovascular adverse event, atrial fibrillation, occurred more frequently in hemoglobin raffimer-treated than in pentastarch-treated patients (37\% vs $17 \%$, respectively). However, the incidence of atrial fibrillation in hemoglobin raffimer-treated patients was within the range of $20 \%$ to $40 \%$ reported for CABG patients, ${ }^{12-15}$ and most of these episodes occurred more than 48 hours after hemoglobin raffimer administration, by which time most (approximately 75\%) of the hemoglobin raffimer had cleared the patients' systems.

Hypertension is a recognized complication in CABG and, depending on their preoperative state, may occur in $30 \%$ to $80 \%$ of patients. ${ }^{16}$ Previous studies have shown that hemoglobin-based oxygen carriers may cause vasoconstric- 
TABLE 5. Mean oxygenation parameters during and after CPB

\begin{tabular}{|c|c|c|c|c|c|c|}
\hline \multirow[b]{2}{*}{ Parameter } & \multicolumn{3}{|c|}{ During 45 min of CPB } & \multicolumn{3}{|c|}{ After CPB } \\
\hline & Hb raffimer & Pentastarch & $P$ value & Hb raffimer & Pentastarch & $P$ value \\
\hline$\dot{\mathrm{V}}_{2}\left(\mathrm{~mL} \cdot \min ^{-1} \cdot \mathrm{m}^{-2}\right)$ & $111.5 \pm 53.8$ & $109.6 \pm 53.4$ & .89 & $167.0 \pm 51.3$ & $161.9 \pm 41.4$ & .67 \\
\hline $\mathrm{Do}_{2}\left(\mathrm{~mL} \cdot \min ^{-1} \cdot \mathrm{m}^{-2}\right)$ & $464.7 \pm 181.8$ & $368.6 \pm 139.9$ & .03 & $643.7 \pm 153.2$ & $679.9 \pm 239.5$ & .49 \\
\hline $\begin{array}{l}\text { Pump flow rate or cardiac } \\
\text { index }\left(\mathrm{L} \cdot \mathrm{min}^{-1} \cdot \mathrm{m}^{-2}\right)\end{array}$ & $3.7 \pm 1.4$ & $3.6 \pm 1.3$ & .78 & $2.5 \pm 0.6$ & $3.2 \pm 1.0$ & .0017 \\
\hline Total $\mathrm{Hb}(\mathrm{g} / \mathrm{L})$ & $85.5 \pm 11.0$ & $69.5 \pm 8.6$ & .0001 & $91.1 \pm 18.1$ & $77.5 \pm 9.7$ & .0006 \\
\hline $\begin{array}{l}\text { Mixed venous oxygen } \\
\text { saturation }(\%)\end{array}$ & $77.2 \pm 8.2$ & $73.3 \pm 7.2$ & .055 & $78.2 \pm 7.0$ & $79.7 \pm 7.0$ & .41 \\
\hline Mixed venous $\mathrm{P}_{2}(\mathrm{~mm} \mathrm{Hg})$ & $47.6 \pm 13.7$ & $40.8 \pm 7.8$ & .023 & $45.2 \pm 6.0$ & $46.6 \pm 6.7$ & .40 \\
\hline Oxygen extraction ratio & $0.26 \pm 0.07$ & $0.30 \pm 0.08$ & .044 & $0.26 \pm 0.07$ & $0.25 \pm 0.07$ & .58 \\
\hline
\end{tabular}

Data are mean $\pm \mathrm{SD} ; t$ test.

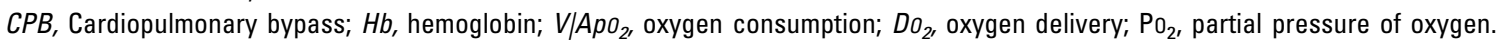

tion and increase mean arterial pressure in a dose-dependent manner. ${ }^{17-20}$ This hemodynamic effect seems to be related to nitric oxide scavenging by the hemoglobin molecule and to the release of endothelin- $1,{ }^{21-24}$ but other (eg, adrenergic) mechanisms may also be involved. ${ }^{25}$ Therefore, an increase in blood pressure, reported more frequently in the hemoglobin raffimer-treated patients, was not unexpected in this study. A nonsignificant increase in blood pressure in hemoglobin raffimer-treated patients relative to pentastarchtreated patients was approximately $5 \%$ to $8 \%(5$ to $10 \mathrm{~mm}$ $\mathrm{Hg}$ ) during the first 24 hours after administration, although there was high variability between the 2 groups. A phase I study reported an approximately 15\% increase in mean arterial pressure in normotensive volunteers who received hemoglobin raffimer. ${ }^{9}$ A concomitant reduction in heart rate, with no associated ECG abnormalities, was also noted in this phase I study. In the current study, investigators were aware that hypertension could occur in the treated groups. Therefore, the reduction in the percentage increase in blood pressure between the hemoglobin raffimer and pentastarch groups was likely the result of more aggressive administration of $\beta$-blockers, calcium channel blockers, or both by the investigators. $\beta$-Blockers were used in $23(77 \%)$ of the hemoglobin raffimer-treated patients compared with $2(7 \%)$ of the pentastarch-treated patients. It seems that hypertension associated with the use of hemoglobin raffimer is common but can be readily managed with conventional antihypertensive medications.

A dose-dependent increase in bilirubin in patients who received hemoglobin raffimer was also expected in this study because the metabolism of cell-free hemoglobin products $^{26}$ is known to cause an increase in bilirubin, a normal product of heme catabolism. The incidence of jaundice was consistent with the dose-dependent increase in total bilirubin reported in the hemoglobin raffimer group. However, the observed increase in total bilirubin was considered mild and was adequately and safely cleared by the liver.
The incidence of MI observed in this study was within the range (2\% to $26 \%$ ) reported perioperatively in CABG patients whose MI was diagnosed by both ECG and creatine kinase/myocardial muscle subtraction criteria, ${ }^{27-29}$ but it was not different between study groups. This is noteworthy in light of the more inclusive criteria used to define an MI in this study (eg, a broader range of ECG changes and a lower threshold of serum creatine kinase/myocardial muscle subtraction levels). The fact that this study was designed to address the dose-response of hemoglobin raffimer may have biased the pooled data against efficacy because the smaller doses are unlikely to result in significant blood conservation. Systemic oxygenation was well maintained in hemoglobin raffimer-treated patients.

This study demonstrated that administration of hemoglobin raffimer reduced the rate of allogeneic RBC transfusion when used in conjunction with IAD in patients undergoing primary CABG surgery. The mean total hemoglobin concentration was approximately $2 \mathrm{~g} / \mathrm{dL}$ higher in the hemoglobin raffimer group than in the control group after the IAD procedure, which may have helped to avoid transfusions in the hemoglobin raffimer group. In patients who required allogeneic RBC transfusions, hemoglobin raffimer-treated patients received a smaller volume (ie, fewer units) than pentastarch-treated patients, even though the harvested volume of acute normovolemic hemodilution blood was comparable in the 2 groups. The difference in allogeneic blood volume received was not statistically significant, perhaps because of the large variation observed in the pentastarch group. A larger sample size will be required to definitively determine whether hemoglobin raffimer leads to a statistically significant reduction in allogeneic blood volume.

This phase II study demonstrated that hemoglobin raffimer up to $1000 \mathrm{~mL}$ was not associated with any serious adverse events in patients undergoing CABG surgery with $\mathrm{CPB}$. In addition, the study suggested that hemoglobin 
raffimer may be an effective oxygen-therapeutic adjunct to other blood-conservation strategies used in CABG surgery to reduce, delay, or avoid allogeneic RBC transfusions. Studies to further characterize the safety and efficacy profile of hemoglobin raffimer as an oxygen-therapeutic adjunct in CABG surgery are warranted.

Statistical analysis was conducted by Nancy Wang, PhD (MacDougal Scientific).

\section{References}

1. Williamson LM, Lowe S, Love EM, Cohen H, Soldan K, McClelland $\mathrm{DB}$, et al. Serious hazards of transfusion (SHOT) initiative: analysis of the first two annual reports. BMJ. 1999;319:16-19.

2. Goodnough LT, Brecher ME, Kanter MH, AuBuchon JP. Transfusion medicine. First of two parts-blood transfusion. N Engl J Med. 1999; 340:438-47.

3. Eagle KA, Guyton RA, Davidoff R, Ewy GA, Fonger J, Gardner TJ, et al. ACC/AHA guidelines for coronary artery bypass graft surgery: a report of the American College of Cardiology/American Heart Association Task Force on Practice Guidelines (Committee to Revise the 1991 Guidelines for Coronary Artery Bypass Graft Surgery). J Am Coll Cardiol. 1999;34:1262-347.

4. Graves EJ. National hospital discharge survey: annual summary, 1991. Vital Health Stat 13. 1993;1-62.

5. Stover EP, Siegel LC, Parks R, Levin J, Body SC, Maddi R, et al. Variability in transfusion practice for coronary artery bypass surgery persists despite national consensus guidelines: a 24-institution study. Institutions of the Multicenter Study of Perioperative Ischemia Research Group. Anesthesiology. 1998;88:327-33.

6. Goodnough LT, Brecher ME, Kanter MH, AuBuchon JP. Transfusion medicine. Second of two parts-blood conservation. $N$ Engl J Med. 1999;340:525-33.

7. Cheng DC. Safety and efficacy of o-raffinose cross-linked human hemoglobin (Hemolink) in cardiac surgery. Can J Anaesth. 2001;48: S41-8.

8. Adamson JG, Bonaventura BJ, Er SS, Jones RT, Langlois SF, MacDonald ID, et al. Production, characterization, and clinical evaluation of Hemolink ${ }^{\mathrm{TM}}$, an oxidized raffinose cross-linked hemoglobin-based blood substitute. In: Rudolph AS, Rabinovici R, Feuerstein GZ, editors. Red blood cell substitutes: basic principles and clinical applications. New York: Marcel Dekker Inc; 1997. p. 335-51.

9. Carmichael FJ, Ali AC, Campbell JA, Langlois SF, Biro GP, Willan AR, et al. A phase I study of oxidized raffinose cross-linked human hemoglobin. Crit Care Med. 2000;28:2283-92.

10. Higgins TL. Quantifying risk and assessing outcome in cardiac surgery. J Cardiothorac Vasc Anesth. 1998;12:330-40.

11. Grover FL, Shroyer AL, Hammermeister K, Edwards FH, Ferguson TB Jr, Dziuban SW Jr, et al. A decade's experience with quality improvement in cardiac surgery using the Veterans Affairs and Society of Thoracic Surgeons national databases. Ann Surg. 2001;234:464-72; discussion 472-4.

12. Almassi GH, Schowalter T, Nicolosi AC, Aggarwal A, Moritz TE, Henderson WG, et al. Atrial fibrillation after cardiac surgery: a major morbid event? Ann Surg. 1997;226:501-11; discussion 511-3.

13. Kolvekar S, D'Souza A, Akhtar P, Reek C, Garratt C, Spyt T, et al.
Role of atrial ischaemia in development of atrial fibrillation following coronary artery bypass surgery. Eur J Cardiothorac Surg. 1997;11: 70-5.

14. Aytemir K, Aksoyek S, Ozer N, Aslamaci S, Oto A. Atrial fibrillation after coronary artery bypass surgery: P wave signal averaged ECG, clinical and angiographic variables in risk assessment. Int J Cardiol. 1999;69:49-56.

15. Borzak S, Tisdale JE, Amin NB, Goldberg AD, Frank D, Padhi ID, et al. Atrial fibrillation after bypass surgery: does the arrhythmia or the characteristics of the patients prolong hospital stay? Chest. 1998;113: 1489-91.

16. Leslie JB. Incidence and aetiology of perioperative hypertension. Acta Anaesthesiol Scand Suppl. 1993;99:5-9.

17. Malcolm DS, Hamilton IN Jr, Schultz SC, Cole F, Burhop K. Characterization of the hemodynamic response to intravenous diaspirin crosslinked hemoglobin solution in rats. Artif Cells Blood Substit Immobil Biotechnol. 1994;22:91-107.

18. Muldoon SM, Ledvina MA, Hart JL, Macdonald VW. Hemoglobininduced contraction of pig pulmonary veins. J Lab Clin Med. 1996; 128:579-84.

19. Rattan S, Rosenthal GJ, Chakder S. Human recombinant hemoglobin (rHb1.1) inhibits nonadrenergic noncholinergic (NANC) nerve-mediated relaxation of internal anal sphincter. J Pharmacol Exp Ther. 1995;272:1211-6.

20. Cheng DCH, Ralph-Edwards A, Mazer CD, Carmichael FJL, Biro GP. The hemodynamic effects of the red cell substitute Hemolink ${ }^{\mathrm{TM}}$ (oraffinose cross-linked human hemoglobin) on vital signs in patients undergoing CABG surgery [abstract]. Anesthesiology. 2000;93:A180.

21. Alayash AI, Fratantoni JC, Bonaventura C, Bonaventura J, Cashon RE. Nitric oxide binding to human ferrihemoglobins cross-linked between either alpha or beta subunits. Arch Biochem Biophys. 1993; 303:332-8.

22. Freas W, Llave R, Jing M, Hart J, McQuillan P, Muldoon S. Contractile effects of diaspirin cross-linked hemoglobin (DCLHb) on isolated porcine blood vessels. J Lab Clin Med. 1995;125:762-7.

23. Schultz SC, Grady B, Cole F, Hamilton I, Burhop K, Malcolm DS. A role for endothelin and nitric oxide in the pressor response to diaspirin cross-linked hemoglobin. J Lab Clin Med. 1993;122:301-8.

24. Ulatowski JA, Nishikawa T, Matheson-Urbaitis B, Bucci E, Traystman RJ, Koehler RC. Regional blood flow alterations after bovine fumaryl beta beta-crosslinked hemoglobin transfusion and nitric oxide synthase inhibition. Crit Care Med. 1996;24:558-65.

25. Gulati A, Rebello S. Diaspirin cross-linked hemoglobin (DCLHB): involvement of adrenergic mechanisms in the pressor effect. Artif Cells Blood Substit Immobil Biotechnol. 1994;22:603-12.

26. Hill SE. Oxygen therapeutics-current concepts. Can J Anaesth. 2001;48:S32-40

27. Jain U. Myocardial infarction during coronary artery bypass surgery. J Cardiothorac Vasc Anesth. 1992;6:612-23.

28. Jain U, Laflamme CJ, Aggarwal A, Ramsay JG, Comunale ME, Ghoshal S, et al. Electrocardiographic and hemodynamic changes and their association with myocardial infarction during coronary artery bypass surgery. A multicenter study. Multicenter Study of Perioperative Ischemia (McSPI) Research Group. Anesthesiology. 1997;86:57691.

29. Randomised trial of normothermic versus hypothermic coronary bypass surgery. The Warm Heart Investigators. Lancet. 1994;343:55963. 